with Ehrlich's reagent (Fig. 2). There is no indication that the Salkowski-positive spots obtained by alkaline treatment could have come from tryptophan as under the same conditions only very small amounts of such substances are derived from high amounts of this aminoacid ( $50 \mathrm{mg}$ ).

In normal living cells the indole crystals can be observed when the algae are put in a hanging drop of the culture medium and the microscope focused at lower levels than the chloroplast layer. In contrast to the active streaming of this layer $\left.{ }^{10}\right)$ there is no visible movement of the crystals. If the cell is submitted to low speed centrifugation in culture medium the chloroplasts are collected at one end of the cell but not the crystals; these remain embedded in an inner "gel" column.

No accumulation of large crystals can be observed in the growing tip of the stalk. They can be easily found in posterior portions of the stalk and in the rhizoid which contains the single nucleus. Growing enucleated anterior parts cut off from nucleated cells shortly before cap-formation are capable of producing the crystalline indole derivative as judged by its presence in the newly formed caps ${ }^{11}$ ) and mainly in their coronae. The crystals remain unaltered in these caps-as well in enucleated stalk portions - when kept in darkness for 7 to 14 days. The natural occurence of this crystalline indole material in Acetabulavia stresses the importance in the search for "bound" auxins ${ }^{12}$ ), 13) in other plants.

I wish to express my gratitude to Prof. J. HämMERLing and to the members of this Institute for their advice and valuable criticism. The author hold a Research Fellowship of the Consejo Nacional de Investigaciones Cientificas y Técnicas, and is an Investigator of the Instituto Fitotécnico de Santa Catalina, Argentine.

Max-Planck-Institut für Meevesbiologie (Abteilung $\mathrm{HÄM-}$ MERLING), Wilhelmshaven, Germany

Eingegangen am 12. Februar 1962

C. J. TANDLER

1) Encyclopedia of Plant Physiology, Vol. 14: Growth and Growth Substances. Berlin-Göttingen-Heidelberg: Springer 1961.-2) Hämmerling, J.: Arch. Protistenkunde 97, 7 (1944). - 3 ) ВетH, K.: Z. Naturforsch. 8b, 334 (1953). _- ) LEITGEB, H.: Sitzber. Kais. Akad. Wiss. Wien, math.-naturw. Cl. Abth. I 96, 13 (1887). 5) Pearse, A. G. E.: Histochemistry. London: J. \& A. Churchill 5) Pearse, A.G. E.: Histochemistry. London: J. \& A. Churchill Nature [London] 186, $237(1960) .{ }^{8}$ ) Goob, N.E., W. A. Andreat and M.W.H. VAN Ysselstein: Plant Physiol. 31, 235 (1956). 9) MAIS, I. M., u. K. MACEK: Handbuch der Papierchromatographie. Jena: Gustav Fischer 1958. - 10) Kamiya, N.: Protoplasmic Streaming. Wien: Springer 1959. - ${ }^{11}$ ) Hämmerlang, H. Clauss,
K. Kecis, G. Richter and G. Werz: Exp. Cell. Res., Suppl. 6, 210 (1959). - 12) Fransson, P.: Physiol. Plantarum [Copenh.] 13 398 (1960). - ${ }^{13}$ Sen Gupta, A., and S. P. SEN: Nature [London] 192, $1290(1961)$.

\section{Entwicklung und Geschlechtsdifferenzierung einer neuen Foraminifere}

Aus Algenmaterial, welches im Frühjahr 1960 in der Nähe der Station Zoologique von Villefranche-sur-Mer (französische Mittelmeerküste) gesammelt wurde, konnte ich eine kleine Rotaliide isolieren und - mit einer pennaten Diatomee als Futter - in Kultur nehmen. Sie erhält den Namen Metarotaliella pavva n.g.n.sp. In ihrer Entwicklung nimmt diese Rotaliide eine Art Mittelstellung zwischen Rotaliella heterocaryotica ${ }^{1 a}$ ) und Rubratella intermedia ${ }^{1 b}$ ) ein. Thre ungeschlechtliche Fortpflanzung entspricht der von Rotaliella heferocaryotica. Es werden drei generative Kerne und ein somatischer Kern ausgebildet. Während die generativen Kerne die Meiose durchführen, schwillt der somatische Kern etwas an, wird dann aber pyknotisch und geht zugrunde. Wenn alle Gonenkerne erhalten bleiben, erzeugt der Agamont zwölf Gamonten. Die geschlechtliche Fortpflanzung beginnt wie bei Rubratella intermedia mit der paarweisen Vereinigung zweier Gamonten. Jeder Gamont bildet eine variierende Anzahl amöboider Gameten aus.

Versuche von Frl. H. WEBER, welche auch eine eingehendere Beschreibung der Entwicklung liefern wird (Archiv f. Protistenk.), führten $z u$ der überraschenden Feststellung, daB sich jeder Gamont mit jedem beliebigen anderen paaren kann, eine geschlechtliche Differenzierung also offenbar nicht für die Paarbildung erforderlich ist.

Zoologisches Institut der Universität, Tübingen

Eingegangen am 13. März 1962

KARL G. GRELI

1) Grell, K. G.: Arch. Protistenkunde a) 100, 268-286 (1954) b) 102, 291-308 (1958).

\section{Wirkung von 2-Desoxy-D-Glucose auf Atmung} und Phosphatgehalt von Hefezellen

Im Rahmen von Untersuchungen über den Atmungs- und Kohlenhydratstoffwechsel von Hefezellen untersuchten wir die Einflüsse von Glucose und Desoxyglucose (DOG) auf die Atmung von Hefezellen (Bäckerhefe). Es wurde gefunden, daß die Atmung von äthanoloxydierenden Hefezellen durch Glucose nicht, wohl aber durch DOG gehemmt wird (Fig. 1)*). In manchen Versuchen verursachte Glucose nicht nur keine Atmungshemmung, sondern sogar eine kleine, aber signifikante Steigerung der Atmung. Wie Äthanolbestimmungen ergaben, ist die durch DOG hervorgerufene Hemmung der Sauerstoffaufnahme bei der Äthanoloxydation auf eine Hemmung der Verwertung des Äthanols zurückzuführen.

Die Atmungshemmung durch DOG ist durch Glucose aufzuheben, wobei schon kleine Konzentrationen Glucose wirksam sind. Die Wirkungen der Fruktose, Mannose und Saccharose, die entweder unmittelbar oder nach enzymatischer Hydrolyse (Saccharose) wie Glucose und DOG Substrate der Hexokinase

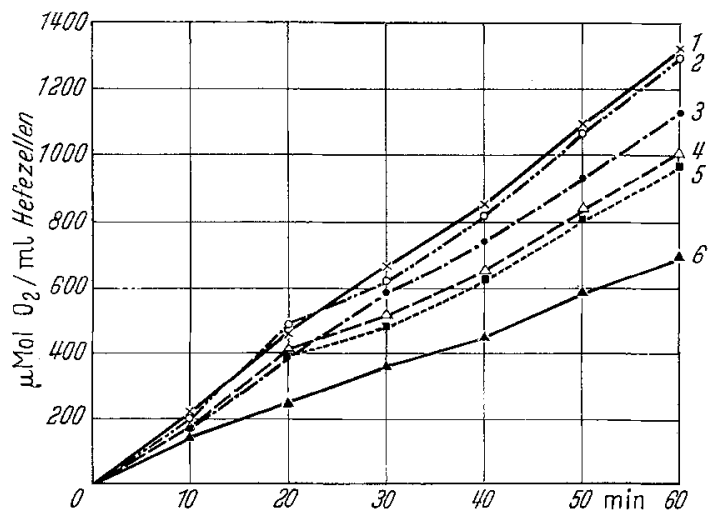

Fig. 1. EinfluB von Glucose und Desoxyglucose auf die Atmung von äthanoloxydierenden Hefezellen. 1 Glucose $\left(10^{-2} \mathrm{~m}\right) ; 2$ Glucose $\left(10^{-2} \mathrm{~m}\right)+\mathrm{DOG}\left(10^{-2} \mathrm{~m}\right) ; 3$ Athanol (Kontrolle); 4 Glucose cose $\left(10^{-2} \mathrm{~m}\right)+$ DOG $\left(10^{-2} \mathrm{~m}\right) ; 3$ Athanol (Kontrolle $; 4$ Glucose
$\left(10^{-3} \mathrm{~m}\right)+\operatorname{DOG}\left(10^{-2} \mathrm{~m}\right) ; 5$ Glucose $\left(5 \cdot 10^{-4} \mathrm{~m}\right)+\mathrm{DOG}\left(10^{-2} \mathrm{~m}\right) ;$ $6 \mathrm{DOG}\left(10^{-2} \mathrm{~m}\right)$

sind und mit großer Geschwindigkeit von den Hefezellen veratmet werden, waren der der Glucose bezüglich der Aufhebung der Atmungshemmung trotz quantitativer Unterschiede qualitativ vergleichbar. Galactose, Xylose, Arabinose, Maltose und Lactose, die entweder nicht oder nur sehr langsam durch Hefezellen verwertet werden können, waren wirkungslos.

Parallel durchgeführte Messungen des Gehaltes der Hefezellen an anorganischem Phosphat zeigen, daß es nach Zugabe von Glucose und DOG zu einem raschen Absinken des anorganischen Phosphates kommt. Auch die kombinierte Zugabe von Glucose und DOG $z u$ Hefezellen führt zu einem entsprechenden Absinken des anorganischen Phosphates (Tabelle).

Tabelle. Wirkung von DOG und Glucose auf den anorganischen Gehalt von Hefezellen. Werte in $\mu \mathrm{Mol} \mathbf{P} / \mathrm{ml}$ Hefezellen $5 \mathrm{~min}$ nach Zugabe des Monosaccharides bzw. Alkohols (stationärer Zustand)

Endogen

+ Athanol $(1,3 \%)$

A

+ Athanol und Glucose $\left(2,4 \cdot 10^{-2} \mathrm{~m}\right)$. . . . . . . . . . 2,3

+ Athanol und DOG und Glucose $\left(\right.$ je $\left.1,2 \cdot 10^{-2} \mathrm{~m}\right) \cdot 1 \cdot-3 \cdot:$
+ Athanol und DOG $\left(1,2 \cdot 10^{-2} \mathrm{~m}\right)+$ Glucose $\left(1,2 \cdot 10^{-3} \mathrm{~m}\right)$

Die Bestimmung des anorganischen Phosphates wurde an Hefezellen durchgeführt, welche durch mindestens 12stündiges Schütteln unter Sauerstoff verarmt wurden.

Die unterschiedlichen Wirkungen der DOG und der Glucose auf die Atmung stehen in einem teilweisen Widerspruch zu den Arbeiten von $K_{\text {IEsow }}{ }^{1}$, der sowohl eine Atmungshemmung durch Glucose ais auch durch DOG bei äthanoloxydierenden Hefezellen fand. Als Ursache für die Atrnungshemmung bei Hefezellen durch DOG diskutiert Kresow die Abnahme des anorganischen Phosphates nach Zufügung dieses Monosaccharides. Die Aufhebung der Atmungshemmung durch Glucose trotz niedrigen anorganischen Phosphats zeigt jedoch, daß Orthophosphat unter den Bedingungen einer intakten Hefezelle keine begrenzende Wirkung auf die Geschwindigkeit der Atmung ausübt. 